\title{
Bronchial asthma in pregnancy
}

\author{
Keywords: Asthma; Pregnancy; Control
}

\section{Short communication}

Bronchial asthma is a very common breathing disorder and is most common chronic respiratory problem of pregnancy affecting upto 8 to $13 \%$ of pregnant females. ${ }^{1}$ There is ample published data that shows that patients with asthma are undertreated during pregnancy even if they were on adequate medications prior to conception. Among women who report having asthma prior to conception only $63 \%$ to $76 \%$ were on asthma medications during their pregnancy. ${ }^{2}$ This change in medication pattern can be explained by change in disease severity during pregnancy with $45 \%$ of females experiencing worsening of symptoms and upto one third of females reporting improvement in their asthma symptoms. ${ }^{2,3}$ One important factor is physician concern for safety of medications and lack of awareness of guidelines. The other important factor is apprehension of the female for use of medications during pregnancy. Guidelines recommend providing written action plan and use of preventer medicines as indicated for any other adult with asthma. ${ }^{3}$ The asthma medications are safe during pregnancy and are FDA pregnancy category B and C. Upto $45 \%$ of females get moderate to severe asthma exacerbation during pregnancy. ${ }^{2}$ Exacerbations are more severe and more frequent in patients with uncontrolled or partially controlled asthma. Pregnant females have higher chances $(1.3 \%)$ of requiring hospitalization for asthma exacerbation than non-pregnant females $(0.8 \%){ }^{2}$ Bronchial asthma exacerbation increases the risk of perinatal complications with females with moderate to severe asthma having increased risk of preterm delivery (RR- 1.54) and Low birth weight (RR-3.02)., ${ }^{4,5}$ Oral steroid use for asthma exacerbation management is associated with significant risk of Preterm delivery (RR-1.51) and low birth weight (RR-1.4) infants. ${ }^{5}$ Babies of asthmatic mothers are also more likely to have congenital anomalies. ${ }^{6,7}$ A recent systematic review and meta-analysis indicated that optimal disease control may reduce these adverse perinatal outcomes. So, proper and timely management of asthma is important in pregnancy to reduce these risk factors.

The goal of management in pregnancy is a safe and healthy mother and child, to maintain normal activities, to prevent chronic day and night symptoms and prevention of exacerbations with medicines that have no or minimal side effects. We also try to prevent fetal hypoxia by preventing maternal exacerbations. A number of pregnancy associated conditions contribute to or modify severity of disease including GERD, nasal congestion and hormonal factors. Since pregnancy is associated with physiological dyspnoea, a fall in $\mathrm{FEV}_{1}$ is better predictor of disease worsening then loss of symptom control. ${ }^{8}$ Regular review of the patients should be done, preconception and every 4 weeks during pregnancy to monitor progress of disease and to maintain it under control and also to assess any associated condition which may cause asthma exacerbations. Patients with mild intermittent symptoms are treated with short acting B2-agonists (SABA) as reliever medications. Inhaled corticosteroids (ICS) are used for persistent asthma as controller medication. Inhaled steroids have been proven to be safe during pregnancy. ${ }^{3,9}$ It is recommended to continue ICS medications in dose that was effective in controlling asthma prior to conception. Data regarding safety of long acting B2-
Volume 3 Issue 3 - 2016

\author{
Manish Garg,' Akhil Jain² \\ 'Department of Respiratory Medicine, Maharaja Agrasen \\ Hospital, India \\ ${ }^{2}$ Department of Medical Oncology, Rajiv Gandhi Cancer \\ Institute \& Research Centre, India
}

Correspondence: Akhil Jain, Consultant Medical Oncologist, Department of Medical Oncology, Rajiv Gandhi Cancer Institute \& Research Centre, Sector-5 Rohini, New Delhi, India, Tel +919990750744, Email akjain1600@gmail.com

Received: September 14, 2016 | Published: December 2I, 2016

agonists (LABA) is still under study. ${ }^{10,11}$ But guidelines say that for baby and mother treating asthma is far more beneficial than the risks associated with use of drugs. ${ }^{3}$ So proper control of asthma is key to safe mother and child in pregnancy.

\section{Acknowledgements}

None.

\section{Conflict of interest}

The author declares no conflict of interest.

\section{References}

1. Murphy VE, Gibson PG, Smith R, et al. Asthma during pregnancy: mechanism and treatment implications. Eur Resp Jour. 2005;25(4):731750 .

2. Murphy VE. Managing asthma in pregnancy. Breathe. 2015;11(4):258267.

3. Global Strategy for Asthma Management and Prevention. Global initiative for asthma (GINA); 2016.

4. Murphy VE, Namazy JA, Powell H, et al. A meta-analysis of adverse perinatal outcomes in women with asthma. BJOG. 2011;118(11):1314 1323.

5. Namazy JA, Murphy VE, Powell H, et al. Effects of asthma severity, exacerbations and oral corticosteroids on perinatal outcomes. Eur Resp Jour. 2013;41(5):1082-1090.

6. Demissie K, Breckenridge MB, Rhoads GG. Infant and maternal outcomes in the pregnancies of asthmatic women. Am J Respir Crit Care Med. 1998;158(4):1091-1095.

7. Murphy VE, Wang G, Namazy JA, et al. The risk of congenital malformations, perinatal mortality and neonatal hospitalisation among pregnant women with asthma: a systematic review and metaanalysis. BJOG. 2013;120(7):812-822.

8. Schatz M, Dombrowski MP, Wise R, et al. Spirometry is related to perinatal outcomes in pregnant women with asthma. Am J Obstet Gynecol. 2006;194(1):120-126. 
9. Tegethoff M, Greene N, Olsen J, et al. Inhaled Glucocorticoids during Pregnancy and Offspring Pediatric Diseases: A national cohort study. Am J Respir Crit Care Med. 2012;185(5):557-563.
10. McCusker $\mathrm{C}$, Hamid Q. Managing asthma during pregnancy. Am J Respir Crit Care Med. 2011;183(6):687-688.

11. Eltonsy S, Kettani FZ, Blais L. Beta2-agonists use during pregnancy and perinatal outcomes: a systematic review. Respir Med. 2014;108(1):9-33. 